\title{
Are reusable boxes beneficial for a sustainable apple cold chain: a precooling analysis
}

Willem Gruyters ${ }^{\left(\mathrm{a}^{*}\right)}$, Thijs Defraeye $^{(\mathrm{b})}$, Pieter Verboven $^{(\mathrm{a})}$, Tarl Berry ${ }^{(\mathrm{c})}$, Alemayehu $\operatorname{Ambaw}^{(\mathrm{a}, \mathrm{c})}$, Umeruzuike Linus Opara $^{(\mathrm{c}, \mathrm{d})}$, Bart Nicolai ${ }^{\left(\mathrm{a}, \mathrm{e}^{*}\right)}$

${ }^{a}$ BIOSYST-MeBioS, Katholieke Universiteit Leuven, Willem de Croylaan 42, B-3001 Leuven, Belgium

${ }^{\mathrm{b}}$ Empa, Swiss Federal Laboratories for Materials Science and Technology, Laboratory for Biomimetic Membranes and Textiles, Lerchenfeldstrasse 5, 9014 St. Gallen, Switzerland

${ }^{\mathrm{c}}$ Postharvest Technology Research Laboratory, South African Research Chair in Postharvest

Technology, Department of Horticultural Science, Stellenbosch University, Stellenbosch 7602, South Africa

${ }^{\mathrm{d}}$ Postharvest Technology Research Laboratory, South African Research Chair in Postharvest Technology, Department of Food Science, Stellenbosch University, Stellenbosch 7602, South Africa ${ }^{\mathrm{e}}$ Flanders Centre of Postharvest Technology, Willem de Croylaan 42, B-3001 Leuven, Belgium *Corresponding authors; email: willem.gruyters@kuleuven.be; bart.nicolai@kuleuven.be 


\section{Response to technical check results}

\section{Comments:}

- A number of symbols used in the manuscript should be collectively provided as a nomenclature list beneath the keyword section.

\section{Reply:}

A table providing the nomenclature is added to the manuscript beneath the keyword section. 
- Apple precooling in plastic crates compared to cardboard standard

- CFD simulations align well with experimental cooling characteristics

- Use of internal packaging materials severely affects cooling performance

- Uniformity of precooling better in plastic crates

- Energy use is significantly less for precooling in plastic crates 


\title{
Are reusable boxes beneficial for a sustainable apple cold chain: a precooling analysis
}

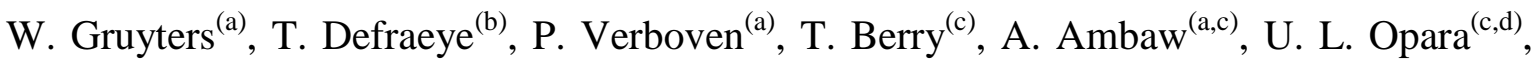 \\ Bart Nicolai ${ }^{\left(\mathrm{a}, \mathrm{e}^{*}\right)}$
}

a BIOSYST-MeBioS, Katholieke Universiteit Leuven, Willem de Croylaan 42, B-3001 Leuven, Belgium

${ }^{\mathrm{b}}$ Empa, Swiss Federal Laboratories for Materials Science and Technology, Laboratory for Biomimetic Membranes and Textiles, Lerchenfeldstrasse 5, 9014 St. Gallen, Switzerland

${ }^{\mathrm{c}}$ Postharvest Technology Research Laboratory, South African Research Chair in Postharvest Technology, Department of Horticultural Science, Stellenbosch University, Stellenbosch 7602, South Africa

${ }^{\mathrm{d}}$ Postharvest Technology Research Laboratory, South African Research Chair in Postharvest Technology, Department of Food Science, Stellenbosch University, Stellenbosch 7602, South Africa

${ }^{\mathrm{e}}$ Flanders Centre of Postharvest Technology, Willem de Croylaan 42, B-3001 Leuven, Belgium

*Corresponding author; email: bart.nicolai@kuleuven.be

\begin{abstract}
Single-use ventilated corrugated cardboard boxes are commonly used in the postharvest apple cold chain but pose significant challenges for optimizing cooling efficiency while reducing energy use. The cooling performance of typical corrugated boxes (standard type 'Mk4') was compared to that of an alternative reusable plastic crate (RPC). Cooling rates, temperature uniformity, energy consumption and fruit quality were evaluated. Using a computational analysis, trade-offs between cooling rates and energy consumption were captured. Experiments were conducted in similar conditions to successfully verify computations and gain additional insights. A mismatch between the position of vent holes and fruit-supporting trays created isolated regions for the airflow, resulting in large temperature heterogeneities in the standard Mk4 box. Both cooling uniformity and energy use were found to be the best for RPCs, but the high airflow rates might cause chilling injury to the apples. Compared to corrugated boxes, RPCs showed promising features towards more sustainable cold chains.
\end{abstract}


Keywords. Computational fluid dynamics; forced-air cooling; apple; cooling performance; energy consumption; package design

\section{NOMENCLATURE}
AFR
Airflow rate
$\mathrm{BC}$
Boundary condition
$\mathrm{CFC}$
Corrugated fibreboard carton
CFD
Computational Fluid Dynamics
CI
Chilling injury
$C_{p}$
Specific heat capacity $\left[\mathrm{J} \cdot \mathrm{kg}^{-1} \cdot{ }^{\circ} \mathrm{C}^{-1}\right]$
$E_{\text {package }}$
Package-related energy use [ $\mathrm{kJ} \mathrm{kg}$ fruit $\left.{ }^{-1}\right]$
FAC
Forced-air cooling
HCT
Half cooling time [h]
$k$
Thermal conductivity $\left[\mathrm{W} \cdot \mathrm{m}^{-1} \cdot{ }^{\circ} \mathrm{C}^{-1}\right]$
$P_{w}$
Fan power $[\mathrm{W}]$
$Q_{\text {air }}$
Flow rate $\left[\mathrm{m}^{3} \mathrm{~s}^{-1}\right]$
RPC
Reusable plastic crate
SECT
Seven-eighths cooling time [h]
SECT $_{\text {avg }}$
Average seven-eighths cooling time over the three layers at a
SECT $_{\text {avg,apple }}$
SECT $_{\text {avg,stack }}$
SST $k-\omega$ model
TOA
$U_{s}$
$\Delta P$
$\rho$

Subscripts

Solid (i.e. the apples)

Plastic (i.e. the RPC)

Carton (i.e. the Mk4)

Fluid (i.e. the air) 


\section{INTRODUCTION}

An elevated temperature is one of the main factors contributing to an early onset of senescence in harvested fresh produce such as apples (Robertson, 2013). Directly after harvest, apples are at temperatures close to the ambient conditions in the orchard or even above on a sunny day. To slow down the postharvest deterioration process, thus to maintain product quality and minimize postharvest losses, a rapid reduction of the temperature of the apples, by removing the field heat, is a crucial first step in the postharvest cold chain (Brosnan and Sun, 2001). The prevalent method for postharvest cooling of apples already packed in shipping boxes is by forcing cold air through palletized stacks of packed produce. This process is called forced-air cooling (FAC). With FAC, a fan is used to create a pressure difference over the stack of boxes, usually arranged on standard sized pallets. As cold air is drawn through the stack, the produce is cooled down by convective heat transfer (Thompson et al., 2008).

The cooling rate of packed apples and the cooling process efficiency are affected by the number, size and position of vent holes in the boxes and their alignment along the flow direction (Pathare et al., 2012). A key parameter here is the total open area (TOA): the surface area on the box sides that is open for air to flow through. Vent hole misalignment of consecutive boxes in the stack can reduce the cooling efficiency as vent holes might be closed off (so lower TOA) or cold air can bypass the fruit via preferential airflow pathways (Berry et al., 2015; Defraeye et al., 2015b; O’Sullivan et al., 2017). Properly designed ventilated boxes, with appropriate vent holes, will result in a fast and uniform cooling of apple box stacks.

Next to cooling efficiency, the design of ventilated boxes also determines the resistance to airflow. The resulting pressure drop over a box stack is directly related to the energy usage of the operating fan to produce a certain airflow rate (AFR) through the boxes (Defraeye et al., 2014). Secondary packaging such as trays often obstructs air movement (de Castro et al., 2004; Ferrua and Singh, 2009; Lu et al., 2016; O'Sullivan et al., 2016). This leads to higher pressure drops and longer cooling times (Ngcobo et al., 2011) and consequently, a higher energy consumption.

Recent experimental research have focused on a few critical aspects of the FAC process such as the cooling dynamics (Defraeye et al., 2013; O'Sullivan et al., 2017; Wu et al., 2018b), aerodynamic resistance of the package design (Ngcobo et al., 2011), product 
quality (Ngcobo et al., 2012) and the economic performance of the cooling process (Ferrua and Singh, 2011). Combining the cooling performance of a box, thus cooling time and uniformity of the packed produce, and its resistance to airflow can often provide key information about the overall cooling efficiency of a specific package design. For this reason, investigating the cooling dynamics of the packed produce should always be accompanied by a simultaneous analysis of the aerodynamic resistance of the box design. Furthermore, such an analysis allows evaluating the overall energy consumption of the FAC operation system of a certain box design, i.e., the package-related energy use during FAC.

Combining the cooling dynamics, the aerodynamic resistance and energy consumption of a certain package design provides a more comprehensive analysis of the overall FAC process. In addition to experiments, numerical modelling with computational fluid dynamics (CFD) is well suited to evaluate package performance. Specific information that is otherwise hard to obtain experimentally can easily be gathered with CFD at a high spatiotemporal resolution. CFD has already shown its merit in improving the precooling of table grapes (Delele et al., 2012), strawberries (Ferrua and Singh, 2011), citrus fruit (Defraeye et al., 2014; Wu et al., 2018a; Wu and Defraeye, 2018) and kiwifruit (O'Sullivan et al., 2017), amongst others.

Currently, corrugated fibreboard is widely used as a packaging material, because of its low production and commercial labelling cost, low weight/volume ratio, cushioning properties that reduce mechanical impact damage and the recyclability of the material (Hanlon et al., 1998). The telescopic corrugated fibreboard carton box (CFC) 'Mk4'-type box is one of the most frequently used boxes for exporting apples from South Africa to other markets in the world (Berry et al., 2015). It is designed with a 'single use' purpose in mind and is discarded after use. Although plastic crates have promising characteristics such as reusability, strength and improved ventilation properties, they are not often used for the export of fresh produce. Recently, Goossens et al. (2018) used a life-cycle assessment to examine the environmental impacts associated with, among others, packaging types of apples. This study showed that altering the packaging type from CFCs, having a 'single use' purpose, to reusable plastic crates (RPCs) at auctions and sorting facilities within a European market would lead to environmental impact reductions up to $46 \%$. The main contributor to the impact was related to the production of the CFCs. Similar annotations were made by Albrecht et al. (2009) for fruit and vegetable transport within Europe and by 
Ingwersen (2012) for the export of pineapples from Costa Rica to US and European markets. Due to a lack of knowledge, the effects of packaging type on final product quality and energy consumption during precooling, storage and transport were, however, not included in their analyses.

The aim of this work was to apply a multi-parameter CFD modelling approach to evaluate these two box design types in a precooling study of 'Granny Smith' apples (Malus $\times$ domestica Borkh. cv. 'Granny Smith'). The Mk4-type box mentioned above and a RPCtype box were evaluated in terms of overall cooling performance, package-related energy consumption. Experiments were conducted to verify computations and to evaluate the impact on chilling injury as a measure for fruit quality, as this is not available from CFD directly. The response of a system of boxes arranged on a pallet to three different airflow rates (AFRs) for precooling were investigated. Additionally, based on the aerodynamic resistance of the stacked package designs, the corresponding package-related energy use ( $E_{\text {package }}$ ) during the different forced-air cooling experiments was computed.

\section{MATERIALS AND METHODS}

\subsection{Apple fruit}

'Granny Smith' apples (Malus $\times$ domestica Borkh. cv. 'Granny Smith') were harvested in April 2013 and stored under controlled atmosphere $\left(1 \% \mathrm{CO}_{2}\right.$ and $\left.1 \% \mathrm{O}_{2}\right)$ at $1{ }^{\circ} \mathrm{C}$ in a commercial farm located in Grabouw (Western Cape, South Africa). The harvested fruit were transported to the Postharvest Technology Lab at Stellenbosch University on August $15^{\text {th }}$ 2013. All apples were free of visual defects. Before the start of the experiments, fruit were stored at $1{ }^{\circ} \mathrm{C}$ in sealed-off polyethylene bags with no perforations in order to reduce moisture loss.

\subsection{Fruit boxes}

In this study, the corrugated cardboard 'Mk4' box design (APL Cartons, Worcester, South Africa) and a reusable plastic crate (RPC; Imoplastic, Marinha Grande, Portugal) were compared. The design and dimensions of the two boxes are given in Figure 1.

The Mk4 is a telescopic, single layer CFC with outer dimensions of $496 \mathrm{~mm} \times 329 \mathrm{~mm}$ $\times 266 \mathrm{~mm}$ and a $3 \mathrm{~mm}$ wall thickness. The short side has two symmetrically placed, vertically oriented, rectangular vent holes at the bottom region and one larger horizontally 
oriented, rectangular vent hole (i.e. the handle) at the top middle region. The long side has two vertically oriented, long rectangular vent holes, positioned symmetrically near the side. The top and bottom vent holes both have a rectangular shape; the top one is smaller than the bottom one. The Mk4 contains four layers of apple fruit each containing 30 apples. In this analysis, the apples were placed on rectangular, expanded foam polystyrene trays. The trays were manufactured with depressions for accommodating individual fruit. The depressions were arranged in rows, which were parallel to the long side of the box, adjacent rows being staggered with respect to one another. There were five rows per tray, each row having six depressions. No extra tray was placed upside down on top of the top apple layer. The total amount of apples stored in the Mk4 was 120 , corresponding to $20.2 \pm 0.7 \mathrm{~kg}$.

The RPC is a polypropylene crate. The external dimensions of the crate are $600 \mathrm{~mm} \times$ $400 \mathrm{~mm} \times 225 \mathrm{~mm}$ with a wall thickness of $3 \mathrm{~mm}$. Both the long and short side have one large vent hole (the handle) in the top middle section of the face and numerous holes on the sides making this crate the most perforated. In this analysis, the RPC contained three layers of apple fruit supported by an expanded foam polystyrene tray. The trays were manufactured with depressions, as in the $\mathrm{Mk} 4$, but the depressions were arranged in rows, which were parallel to the short side of the box. Adjacent rows were staggered with respect to one another as well. There were nine rows per tray with four or five fruit per row as 4-54-5-4-5-4-5-4 (Tray A) or 5-4-5-4-5-4-5-4-5 (Tray B) arrangement. Hence, the number of fruit per tray could be 40 or 41 . The middle tray was of type Tray B with 41 apples whereas the other two layers were of type Tray A with 40 apples each. No extra tray was placed upside down on top of the top apple layer. The total amount of apples stored in the RPC was 121 , corresponding to $20.4 \pm 0.7 \mathrm{~kg}$. Table 1 summarizes the loading capacities and vent hole characteristics of the two box designs.

\subsection{Pallet stacking}

Figure 2 illustrates the stacking pattern of each of the two fruit box designs on a pallet. Table 2 summarizes the stack characteristics. The whole stack was placed on a standard wooden ISO-pallet with dimensions $1200 \mathrm{~mm} \times 1000 \mathrm{~mm}$. While in practice high stacks are used, this analysis considers a stack of Mk4 consisting of three identically stacked layers, each containing seven boxes. The stack of RPC consisted of four identically stacked layers each containing five boxes. The relative large headspace of the RPC makes this particular box design less volumetrically efficient compared to the Mk4. 


\subsection{Forced-air cooling experiments}

All stacks were first equilibrated to ambient air conditions to a temperature of about 25 ${ }^{\circ} \mathrm{C}$. Each stack was then individually placed in front of a FAC system, located inside a cool store and was aligned with a metal plenum. This created an airspace of $120 \mathrm{~mm}$ between the stack and the back plate. Next, all the sides parallel to the airflow direction (i.e., $x y$ - and $y z$-planes) were sealed with plastic sheets to ensure that there was only airflow through the stack in the horizontal (positive $y$-) direction. The FAC airflow was regulated to obtain three AFRs lying within range of what is commonly used in the precooling industry (ASHRAE, 2010; Brosnan and Sun, 2001; de Castro et al., 2004; Thompson et al., 2008). The temperature and relative humidity of the cool stores were kept at $0.0 \pm 1.0^{\circ} \mathrm{C}$ and 81.4 $\% \pm 6.3 \%$, respectively, for all experiments. The FAC system uses a centrifugal fan (KDD 10/10 750W 4P-1 3SY, AMS supplies, Sandton) for sucking air through the stack. The pressure drop over the stack was measured with a differential pressure meter (Air Flow Meter Type A2G-25/air2guide, Wika, Lawrenceville GA 30043, USA, accuracy of \pm 1 Pa). Three replications of each experiment were conducted. The obtained superficial air velocities and measured pressure drops over the box stacks are presented in Table 3.

The temperature of several apples in the stack was monitored every $300 \mathrm{~s}$ ('sample fruit'). Fruit pulp temperatures inside the Mk4 were measured with T-type thermocouples, accuracy of $\pm 0.025 \%$ (Thermocouple products Ltd, Edenvale, South Africa) inserted into the core of the sample fruit. For the RPC, the fruit pulp temperatures were monitored with a LogTag ${ }^{\circledR}$ Haxo-8 Humidity \& Temperature Recorder, accuracy of $\pm 0.1{ }^{\circ} \mathrm{C}$ (LogTag Recorders Ltx., Auckland, New Zealand). The relative positions of the sample fruit in the stack are shown in Figure 3. Due to experimental constraints, all sample fruit were located on the top tray in the box. For the stack of the Mk4, one sample fruit per box was used for temperature measurements and three apples for weight loss measurements, around each sample position. In total, the temperatures of 21 apples and the weight losses of 63 apples were logged. For the RPC stack, two sample fruit per box were used for temperature measurements and three apples for weight loss measurements, around each sampling position. For the RPC, the sample fruit were positioned in layers 1, 3 and 4 . In total, the temperature of 30 apples and the weight loss of 45 apples were measured. For each box design, the weight loss during FAC of more than $20 \mathrm{~h}$ was found to be negligible (data not shown). 


\subsection{Data analysis}

The cooling behaviour of horticultural produce can be analysed by normalising the time-temperature history to the fractional unaccomplished temperature difference (Eq. 1)

$$
Y=\frac{T-T_{m}}{T_{i}-T_{m}}
$$

where subscripts $i$ and $m$ represent initial temperature of the fruit and the set cooling medium (i.e., the supply air in the cold store) temperature, respectively, $T$ indicates the temperature at a certain time in the core of the sample fruit $[\mathrm{K}]$. Eq. 1 enables comparing cooling processes with different initial fruit or cooling air temperatures (Anderson et al., 2004).

Based on the measured temperature profiles of the sample fruit, a satisfactory approximation of the cooling performance was obtained. Two parameters that are commonly used throughout the postharvest industry are the half cooling time (HCT) and the seven-eighths cooling time (SECT). These parameters indicate the time required to cool down the produce to a temperature value that is half $(Y=0.500)$ or seven-eighths $(Y=0.125)$ from the initial temperature difference between produce and cooling air (Brosnan and Sun, 2001; Defraeye et al., 2015a). They are a characteristic of the cooling process over that time and, therefore, well suited to compare different cooling situations. Of particular interest in commercial (pre)cooling operations is the SECT because it depicts the moment in time when the temperature of the produce lies reasonably close to the required storage temperature (Brosnan and Sun, 2001). Once the SECT is reached, the produce is placed inside conventional storage facilities where the remaining heat is removed with less energy costs (Brosnan and Sun, 2001). For optimal storage, apples should be cooled within one or two days after harvest because they deteriorate about the same in one day at field temperatures as they do in one week at proper storage temperatures (depending on the cultivar between $-1{ }^{\circ} \mathrm{C}$ and $4{ }^{\circ} \mathrm{C}$; ASHRAE, 2006). The measured data was evaluated with a one-way ANOVA to identify significant differences. This analysis was performed with Matlab 8.4.0 (R2014b - The Mathworks, Natick, CT, USA).

The energy consumption during FAC was determined based on the pressure loss over the packaging and the required cooling time of the produce, which in turn depends on the box design. In order to assess the overall cooling efficiency of a certain package design, the 
package-related energy consumption $E_{\text {package }}$, required by the FAC unit to force cold air through the stack of boxes during the experiments was estimated. Since the stack dimensions varied from one package type to the other, the superficial air velocity was used to compare the ventilation rate of the different stacks, which is defined by Eq. (2):

$$
U_{s}=\frac{Q_{a i r}}{l_{x} \cdot l_{z}}
$$

where $U_{s}$ is the superficial air velocity $\left[\mathrm{m} \mathrm{s}^{-1}\right]$ (see Table 3 ), $Q_{\text {air }}$ the flow rate $\left[\mathrm{m}^{3} \mathrm{~s}^{-1}\right]$ and $l_{x}$ and $l_{z}$ the length of the stack in the corresponding $\mathrm{x}$ - and z-axis.

The beneficial effect of increasing the AFR on the cooling time was assessed as well. An estimation of the fan power $P_{w}[\mathrm{~W}]$ that is required to force cold air through a stack of packaging during the experiments was calculated as the product of the pressure drop $\Delta P$ $[\mathrm{Pa}]$ over the stack with the flow rate $\left(Q_{\text {air }}\left[\mathrm{m}^{3} \mathrm{~s}^{-1}\right]\right)$ :

$$
\begin{gathered}
P_{w}=Q_{a i r} \cdot \Delta P \\
\Delta P=a \cdot U_{s}^{b}
\end{gathered}
$$

where $a$ and $b$ are the resistance coefficient $\left(\mathrm{kg} \mathrm{s}^{b-2} \mathrm{~m}^{b+2}\right)$ and exponent of the Ramsin equation, respectively (Chau et al., 1985; Ngcobo et al., 2011). These parameters depend on the box porosity, fruit diameter and stacking pattern of the produce (Delele et al., 2008).

The $E_{\text {package }}$ required to cool the produce down for each experiment with a different AFR was estimated by multiplying the calculated fan power (Eq. 3) with the required precooling time. For the latter, the average SECT of the entire stack $\left(\mathrm{SECT}_{\text {avg,stack }}\right)$ for each box design was taken in this study. Both the fan power required to produce a certain airflow (i.e., $P_{w}$ ) and the time needed to maintain this airflow (i.e., $\mathrm{SECT}_{\text {avg,stack }}$ ) are influenced by package design (Defraeye et al., 2014). Note, however, that this calculated $E_{\text {package }}$ only includes the contribution of the stack of packaging and not the contributions of other components involved in the cooling system (e.g., see de Castro et al., 2005). 


\subsection{Numerical modelling procedure}

\subsubsection{CFD model}

Computational models of each experimental setup were constructed. In order to reduce computational cost, only a single layer in the middle of each stack was considered by assuming periodicity in the stack. A periodic boundary condition (BC) was implemented at the top and bottom side of the single layer to simulate heat transfer between the different layers of the stack. All apple fruit were modelled discretely as regular spheres with a $3.6 \mathrm{~cm}$ radius. The physical transport phenomena in the airspaces between the fruit were explicitly resolved. Figure 4 illustrates the computational domain with the implemented BCs, simulating horizontal FAC. Both fruit and box designs were modelled as solid domains while the free-stream air was a fluid domain. The thermophysical model parameters of the fruit, Mk4, RPC and air were assumed temperature independent due to the relatively small temperature range (Ferrua and Singh, 2009), and are given in Table 4 (Ashby et al., 2009; Ho et al., 2010; Ramaswamy and Tung, 1981).

If the cooling process requires maximally $20 \mathrm{~h}$, the total heat flow rate from the apples is about $20.3 \mathrm{~W}$ on average. This is determined based on an initial heat load of a single box of about $1.5 \mathrm{MJ}$, which is calculated by multiplying the total mass of the packed apples with its specific heat capacity and temperature difference of $25{ }^{\circ} \mathrm{C}$ to reach the required storage temperature. Here, the initial respiration heat generation in a single box is about 2.7 W (ASHRAE, 2010; $20.2 \mathrm{~kg}$ apples at $25.0{ }^{\circ} \mathrm{C}$ ). However, the contribution of respiratory heat to the total heat load is only relevant for prolonged precooling operations (Redding et al., 2016) which was not the case here (see Table 6). Therefore, respiration heat generation was not taken into account in the model (Gowda et al., 1997; Tanner et al., 2002). Due to the negligible weight loss during FAC (Tanner et al., 2002), the latent heat removal by moisture evaporation at the surface of the fruit was assumed insignificant. In addition, buoyancy effects and radiation were assumed to have a minimal effect in FAC processes (Defraeye et al., 2013) and were also not taken into account.

The inlet was modelled as a uniform velocity $\mathrm{BC}$ with a fixed temperature around $0{ }^{\circ} \mathrm{C}$ and medium turbulence intensity (5\%). Three superficial airflow velocities used in the experiments were applied (see Table 3). The air domain outlet was modelled as a zero static pressure BC. By making the up- and downstream sections sufficiently large, the influence of these boundaries on the flow near the stacked boxes was minimised. The trays were 
modelled with rounded corners, and a thickness of $2 \mathrm{~mm}$. They were subtracted from the air domain creating isolated layers. Where they sliced the fruit at a fruit height of about oneseventh of the fruit diameter, they were deleted using a Boolean operation. Since the bottom face vents of the boxes were blocked by the presence of a tray, these vent holes were not taken into account. In addition, the bottommost tray was not taken into account. Both trays and box BCs were modelled as adiabatic, no-slip walls with zero roughness. The Reynolds-averaged Navier-Stokes (RANS) equations combined with the shear stress transport $k-\omega$ turbulence model (SST $k-\omega$ model) and wall functions were solved. This turbulence model was validated previously for a very similar computational setup (Ambaw et al., 2012; Defraeye et al., 2013; Delele et al., 2013, 2008; Han et al., 2015; Wu et al., 2018a).

\subsubsection{Solution procedure}

All domains were discretised using a hybrid mesh grid with tetrahedral and hexahedral mesh cells. In total, the Mk4 and RPC have $5.60 \times 10^{6}$ and $8.45 \times 10^{6}$ mesh cells. To calculate the spatial discretization error, a grid sensitivity analysis with Richardson extrapolation was performed (Celik et al., 2008; Franke et al., 2007; Roache, 1994). For the pressure drop over the stack and the surface-averaged heat transfer coefficients of the fruit, the spatial discretisation error was maximally $0.65 \%$ for both the Mk4 and RPC. The model transport equations were solved using the finite volume technique of ANSYS CFX 19.0. The iterative procedure was evaluated by monitoring the velocity and temperature at certain locations in the flow field, as well as the mass imbalance and the turbulent kinetic energy. First, the mass and momentum equations were solved after which a converged steady-state solution for the airflow was used as an initial condition to solve the unsteady heat transfer equations. Based on a temporal sensitivity analysis, a time step of $150 \mathrm{~s}$ with 35 iterations was selected for the transient simulations. The advection scheme used a highresolution spatial differencing scheme and the transient scheme the second-order backward Euler method which is an implicit time-stepping scheme that is second-order accurate (ANSYS, 2016). All calculations were performed on a 64-bit Intel® Xeon® CPU E5-2630, $2.30 \mathrm{GHz}, 128 \mathrm{~GB}$ RAM, Windows 10 PC. All transient simulations (for a period of $24 \mathrm{~h}$ after cooling) took more than $56 \mathrm{~h}$ to complete. 


\section{Results}

\subsection{Pressure drop characteristics and airflow patterns}

Generally, the pressure drop over a certain package design or stack is inversely related to the TOA, and increasing the AFR implies a noticeable increase in pressure drop (Ngcobo et al., 2011; van der Sman, 2002). Both the experimental and numerical pressure drop curves over the stack are shown in Figure 5 for each box design as a function of the AFR. The corresponding power-law approximation is also shown (Eq. (4)). The larger pressure drop of the Mk4 stack compared to that of the RPC is evident. The latter has a very open box wall design with abundant vent holes distributed well over each side (high TOA) resulting in a reduced airflow resistance and limited obstructions. On the contrary, the Mk4 has a low TOA on both its short and long sides, causing a high resistance to airflow.

Figure 6 depicts velocity contour plots on three distinct vertical planes in the stack at a low AFR. In the RPC CFD model, it is observed that the large hand hole on the sides is positioned right above a tray, causing a large portion of the incoming airflow to pass over the top apple layer. Here, the box porosity on the top of the box is considerably higher than in the rest of the RPC. This created a channel flow and an airflow shortcutting. In the Mk4 boxes, $36.50 \%$ of the incoming airflow entered the front of the stack via the left side, while the remaining portion was evenly divided between the centre and right part (31.75\%). There was only limited lateral airflow exchange between adjacent boxes. In addition, the vent hole design is not properly matched to enable equal airflow access to the zones between the supporting trays. Due to the blockage effect of the trays, two distinct velocity regions clearly develop inside the boxes: apples on the top and bottom tray are isolated from the air that only flows through the middle layers.

Table 5 presents power-law approximations of the pressure drop curves. Based on a regression analysis of the three replications per experiment, the Ramsin relation (Eq. 4) was found to be statistically significant for each box designs ( $p \geq 0.98$ ). For both the Mk4 and RPC experiments, the resistance coefficient $(a)$ of the Ramsin equation was smaller than for the model. Furthermore, the RPC experiments showed a linear relation with a resistance exponent close to one, while all other cases showed coefficients close to two. The low pressure drop differences over the considered velocity range and large variation between repetitions (standard deviation of $3 \mathrm{~Pa}$ ) made it difficult to discern the expected quadratic relationship. However, the CFD model clearly showed this. The high-velocity channel flow 
above the top apple layer (see Figure 6) and airflow between individual boxes caused by the depressions on all RPC sides (see Figure 1) create airflow shortcuts leading to small pressure drops. Since the CFD models represented the ideal situation, there was also an idealised vent hole alignment in the stack and no gaps between the individual boxes. However, in practice, this is not the case. Improper stacking and misalignment of vent holes in consecutive boxes could reduce the intrinsic permeability of the stacks. In addition, gaps between the individual boxes can occur, creating possible preferential airflow paths that bypass the fruit, reducing airflow resistance.

\subsection{Cooling rate and temperature uniformity}

\subsubsection{Spatial temperature distribution at low airflow rates}

Temperature contour plots at three distinct vertical planes in the stack after $2 \mathrm{~h}$ of cooling at low AFR are depicted in Figure 6. In addition, Figure 7 shows the average SECT values of each sample fruit in a single layer $\left(\mathrm{SECT}_{\mathrm{avg}, \mathrm{apple}}\right)$ at low AFR, both from the experiments and the CFD model.

Between the Mk4 boxes located in the front row, there was a significant difference $(\mathrm{p}<$ 0.001) between the left box (3) and the other two boxes (1 and 2). Similarly, at the back row, there was a distinct difference $(\mathrm{p}<0.001)$ between the left box $(5)$ and the right two boxes ( 6 and 7) but not between box 6 and 7. Furthermore, the left row of the Mk4 stack cooled significantly slower in comparison to the centre and right row of the stack. In the left row, the cold air enters the box via the long side, which had two oblong ellipse shaped vent holes, with a combined TOA of $3 \%$. For the other two rows on the right, the cooling air passed through three vent holes on the short side of the box, which had a combined TOA of $3.6 \%$. In addition, the left row comprised three boxes while the other two rows (centre and right) only had two boxes. The initial heat load that needed to be extracted in the left row was thus much higher in comparison to the other two rows, leading to an increase in SECT. Apparently, there was no significant difference in $\mathrm{SECT}_{\text {avg,apple }}$ between box 4 and $5(\mathrm{p}=0.88)$. Hence, the cooling rate of the left row of the Mk4 stack was more heterogeneous laterally while the centre and right more along the depth. In addition to the lateral temperature heterogeneity, large temperature differences develop in the vertical direction due to the presence of trays. This is illustrated in Figure 6 where a cold zone in the middle and warmer zone in the top/bottom of the boxes is visible. 
It is clear that the design of the RPC has the largest TOA and thus is most beneficial for the lateral cooling uniformity. The $\mathrm{SECT}_{\mathrm{avg}, \text { apple }}$ of the RPC clearly increased with depth. The difference in SECT $_{\text {avg }}$ between the front and middle position was $40 \%$ ( $\mathrm{p}$ < 0.001). The apples that are located in the back row (boxes 4 and 5) but near the middle of the RPC layer cooled faster than the apples located on the sides. These SECT $_{\text {avg,apple }}$ values were even comparable with those of the middle row. Air entering the RPC stack followed a preferential path along the top of the middle box (2) and exited this box through the large hand holes while guiding the cold air over middle parts of boxes 4 and 5 in the stack. Thus, the temperature differences were mainly in the airflow direction. These differences were caused by heat uptake from the fruit as the air passed through the stack, resulting in slower cooling at the back. In addition, the presence of trays caused vertical temperature heterogeneity.

\subsubsection{Cooling time}

The temperature distribution is further presented in terms of the obtained SECT of the monitored fruit in function of its position in the flow direction. Three different positions in a single layer of the stack were considered, namely front, middle and back according to the three streamwise positions in Figure 7. The average SECT over the three layers at each position was calculated $\left(\mathrm{SECT}_{\mathrm{avg}}\right)$. Also, it should be noted that the middle position for the Mk4 only had a single value per layer.

Figure 8 depicts the experimentally measured and numerically calculated $\mathrm{SECT}_{\text {avg }}$ at three different streamwise positions for each box design as a function of the AFR. It is clear from section 3.2.1 that there was a high degree of temperature heterogeneity inside a single layer of packages. The highest $\mathrm{SECT}_{\text {avg }}$ values were located upstream while the lowest values downstream. Increasing the AFR decreased the $\mathrm{SECT}_{\mathrm{avg}}$ in all three positions in the layer. The lateral temperature differences in the Mk4 stack also explain the high standard deviation of the average values for the Mk4 at all three positions. Due to the large standard deviations shown for the Mk4, it can be concluded that the overall temperature distribution inside the RPC layer was more uniform than in the Mk4.

Table 6 presents the experimentally obtained and numerically calculated SECT $_{\text {avg,stack }}$ of each box design, based on the temperature profiles of all the sample fruit combined ("point value"). In addition, the volume averaged temperature profile of all fruit in the single layer of the stack can also be calculated with CFD ("volume value"). Significant 
differences between point and volume values were observed. Following the temperature history during cooling is clearly influenced by the specific position in the individual boxes and throughout the stack. Based on the volume averaged temperature profiles, the Mk4 stack showed a lower $\mathrm{SECT}_{\text {avg,stack }}$ for all AFRs, while a higher value was calculated for the RPC. The small vent holes of the Mk4 box created jets of cold air that rapidly cooled apples in front of the vents (i.e., the middle region of the box). Due to the presence of the trays, the cooling uniformity, however, drastically decreased.

\subsection{Quality observations}

In general, moisture loss during FAC operations can be neglected where the cooling process is fast (Tanner et al., 2002). In the experiments, less than $0.04 \%$ moisture loss after reaching the SECT was measured in all cases. After the FAC experiments at the highest AFR, chilling injury (CI) symptoms (discolouration of the fruit skin) were observed in the RPC stack but not in the Mk4 stack. In total, $5.28 \%$ of all the apples in the RPC stack showed signs of CI. This could be an indirect effect of the AFR but also a direct result of or in combination with - the low room temperatures during these experiments $\left(0{ }^{\circ} \mathrm{C} \pm 1{ }^{\circ} \mathrm{C}\right)$ (ElMasry et al., 2009). Additional experiments are needed to ascertain the correct explanation for this observation.

\subsection{Energy consumption}

Combining the pressure drop and the $\mathrm{SECT}_{\mathrm{avg}}$ characteristics for each box design allows estimating the energy use $E_{\text {package }}$ of each box during FAC (see section 2.5). Figure 9 depicts the energy use that is required to maintain the fixed AFRs through each box configuration, based on the $\mathrm{SECT}_{\mathrm{avg}, \mathrm{stack}}$ point values in Table 6. The lowest energy requirement was found for the RPC. Increasing the AFR from a low to medium value required 6.63 and 3.19 times more energy for the Mk4 and RPC, respectively, while lowering the $\mathrm{SECT}_{\text {avg }}$ profoundly (see Table 6). The low TOA of the Mk4 boxes obviously caused a large energy requirement to drive the cooling air through the stack. As mentioned before, there might be considerable misalignment of vent holes in practice, leading to a reduced airflow path in the Mk4 stack. The RPC, on the other hand, is a highly porous box, with lots of vent holes on every side, which can also be aligned easily. Accordingly, the required AFR for the RPC could be attained by applying a much lower pressure drop. Consequently, there was a much lower energy consumption. 
Generally, there was only a small improvement on the $\mathrm{SECT}_{\text {avg }}$ for both box designs highest value decreased the $\mathrm{SECT}_{\mathrm{avg}}$ by $16 \%$ to $19 \%$, while demanding up to three times more energy. Thus, increasing the AFR above a certain value is an ineffective way to improve the precooling operation.

\section{Discussion}

\subsection{Comparison of cooling performance of the two box designs}

With the Mk4 box design, both lateral and horizontal temperature heterogeneity was observed whereas only horizontal heterogeneity was visible with the RPC design. At low AFRs, the RPC box design clearly performs the best in terms of cooling uniformity. The consequence of the higher TOA of the RPC is that at the same superficial air velocity, the local air velocity through the vents was lower than in the Mk4 design. Local cooling rates of fruit near the vent holes may thus be somewhat lower as local convective heat transfer coefficients are smaller (Defraeye et al., 2014). Particularly at higher AFRs, the Mk4 design has smaller SECTs at the expense of higher energy use requirements, as was also experimentally observed.

\subsection{Effect of vent hole misalignment and gaps between the boxes}

The Mk4 has a telescopic design by which the vent holes in the inner and outer box frequently did not align properly in the experimental trials. It was observed that there was often an overlap between the two, causing smaller vent holes on the sides in practice than in the design and CFD simulations. This potentially lowered the TOA and disrupted the alignment of vent holes between adjacent boxes. In addition, small gaps between the individual Mk4 boxes in the stack were present, leading to a lower pressure drop but also reduced cooling rates. This appeared to be a disadvantage common to CFCs that easily deform under the load and are affected by moisture uptake (Berry et al., 2018; Pathare et al., 2016). In addition, the stack configuration on the pallet can also influence the horizontal air distribution throughout the stack (O'Sullivan et al., 2017). For the Mk4, only a small portion of the airflow entering the front of the pallet flowed to the lateral adjacent boxes while the main part of the airflow was pulled from the front towards the back of the pallet, a phenomenon also observed by O'Sullivan et al. (2016). 


\subsection{Impact of using fruit-supporting trays}

Both box designs in this study have apple-supporting trays. As mentioned before, these trays can either guide or obstruct the airflow in a certain way. This could lead to either an improved cooling uniformity or develop more cooling heterogeneity within a single box and layer (Berry et al., 2016). The latter phenomenon was most apparent in the Mk4 during horizontal FAC. Here, the combination of its vent hole design with the use of trays create isolated regions of low airflow velocity, which result in slower cooling rates. To a lesser extent, this effect was also visible in the RPC. However, during refrigerated transport in the postharvest cold chain, a vertical airflow at low AFR ensures the cooling of fruit (Defraeye et al., 2015b; Wu et al., 2018a). This poses extra challenges for the packaging industry as supporting trays now completely block vertical airflow. Future produce packaging research should, therefore, be directed to allow proper air distribution during vertical and horizontal cooling while still maintaining its mechanical integrity. In addition, it is crucial to adapt box designs to accommodate fruit-supporting trays if they are used in different phases of the postharvest cold chain. Trays can also act as an extra cushioning material within the box to prevent or minimise mechanical damage during handling and transportation (Fadiji et al., 2016). Since RPCs lack the cushioning properties that CFCs have, this might be a crucial aspect for RPCs and should be further investigated.

\subsection{Sustainable packaging in the postharvest cold chain}

Although corrugated carton boxes are well-established packaging materials in the postharvest cold chain, their single-use purpose and large energy requirements for cooling make them less sustainable (Albrecht et al., 2009; Berry et al., 2015; Defraeye et al., 2014; Goossens et al., 2018). With the current paradigm shift towards a more sustainable postharvest cold chain, deploying RPCs proves to be a good alternative. With the existence of the European pool system, it becomes possible to successfully implement RPCs in the cold chain. Within this system, there are central distribution facilities where the RPCs are inspected and washed before re-use. Therefore, currently used CFC box designs can easily be replaced and improved with RPCs, for example, by adding more vents without compromising their structural strength or by tuning their positions to the presence of trays. Besides the RPCs beneficial overall cooling performance illustrated in this study, they are easy to stack in a consistent manner on a pallet, reducing manual labour time. In addition, they can be re-folded after use in order to reduce space. 


\section{Conclusions}

A multi-parametric CFD modelling approach was used to assess the overall cooling behaviour of a corrugated carton 'Mk4'-type box and a RPC, both with apple-supporting trays. A series of forced-air cooling experiments were conducted to study the combined effects of superficial air velocity and box design on the cooling behaviour of South African 'Granny Smith’ apples.

In general, using supporting trays has a clear impact on both airflow and cooling performance of a certain package design. When using such trays, package and vent hole design should be adapted accordingly to avoid developing isolated areas in the box from the airflow, as was the case with the Mk4. In combination with the proper vent hole design, it can clearly decrease the resistance to airflow but also improve cooling uniformity as was observed in the RPC. Based on the ease of stacking, the hydrodynamic and thermodynamic performances, the RPC was relatively best. This study clearly illustrates the merit of using reusable plastic crates in cooling processes of apples. This is a good step towards developing a more sustainable and energy efficient postharvest cold chain.

\section{Acknowledgements}

The financial support of the Flanders Innovation \& Entrepreneurship (Project VLAIO 120745) is kindly appreciated. This work is based upon research supported by the South African Research Chairs Initiative of the Department of Science and Technology and National Research Foundation. Acknowledge is also due to the South African Postharvest Innovation Program (PHI) and Hortgro ${ }^{\text {Science }}$ through research project awarded to Prof. U. L. Opara on "Packaging of the Future". Thijs Defraeye acknowledges the support of the Swiss National Science Foundation SNSF (project 200021_169372).

\section{References}

Albrecht, S., Beck, T., Barthel, L., Fischer, M., 2009. The sustainability of packaging systems for fruit and vegetable transport in Europe based on life-cycle-analysis update 2009. Michendorf, Germany.

Ambaw, A., Verboven, P., Delele, M.A., Defraeye, T., Tijskens, E., Schenk, A., Nicolai, B.M., 2012. CFD Modelling of the 3D Spatial and Temporal Distribution of 1- 
methylcyclopropene in a Fruit Storage Container. Food Bioprocess Technol. 6, 22352250. doi:10.1007/s11947-012-0913-7

Anderson, B.A., Sarkar, A., Thompson, J.F., Singh, R.P., 2004. Commercial-scale forcedair cooling of packaged strawberries. Trans. ASAE 47, 183-190.

ANSYS, 2016. ANSYS CFX 17.2 Reference Guide. ANSYS, Inc., Canonsburg, PA, USA. Ashby, M., Messler, R., Asthana, R., Furlani, E., Smallman, R.E., Ngan, A.H.W., Crawford, R.J., Mills, N., 2009. Engineering materials and processes desk reference, First edit. ed. Butterworth-Heinemann, Oxford, UK.

ASHRAE, 2010. ASHRAE Handbook: Refrigeration, SI Edition. ed. American Society of Heating, Refrigerating and Air-Conditioning Engineers, Atlanta.

ASHRAE, 2006. ASHRAE Handbook: Refrigeration, SI edition. ed. American Society of Heating, Refrigerating \& Air-Conditioning Engineers, Atlanta.

Berry, T., Defraeye, T., Nicolai, B.M., Opara, U.L., 2016. Multiparameter analysis of cooling efficiency of ventilated fruit cartons using CFD: impact of vent hole design and internal packaging. Food Bioprocess Technol. doi:10.1007/s11947-016-1733-y

Berry, T., Delele, M.A., Opara, U.L., Griessel, H., 2015. Geometric design characterisation of ventilated multi-scale packaging used in the South African pome fruit industry. Agric. Mech. Asia, Africa, Lat. Am. 46, 34-42.

Berry, T.M., Ambaw, A., Defraeye, T., Coetzee, C., Opara, U.L., 2018. Moisture adsorption in palletised corrugated fibreboard cartons under shipping conditions: a CFD modelling approach. Food Bioprod. Process. doi:10.1016/j.fbp.2018.11.006

Brosnan, T., Sun, D.W., 2001. Precooling techniques and applications for horticultural products - a review. Int. J. Refrig. 24, 154-170.

Celik, I.B., Ghia, U., Roache, P.J., Freitas, C.J., 2008. Procedure for estimation and reporting of uncertainty due to discretization in CFD applications. J. Fluids Eng. 130, 
4. doi:10.1115/1.2960953

Chau, K. V., Gaffney, J.J., Baird, C.D., Church, G.A., 1985. Resistance to Air Flow of Oranges in Bulk and in Cartons. Trans. ASAE 28, 2083-2088. doi: $10.13031 / 2013.32570$

de Castro, L.R., Vigneault, C., Cortez, L.A.B., 2005. Effect of container openings and airflow rate on energy required for forced-air cooling of horticultural produce. Can. Biosyst. Eng. 47, 1-9.

de Castro, L.R., Vigneault, C., de Cortez, L.A.B., 2004. Effect of container opening area on air distribution during precooling of horticultural produce. Trans. ASAE 47, 20332038.

Defraeye, T., Cronjé, P., Berry, T., Opara, U.L., East, A., Hertog, M., Verboven, P., Nicolai, B., 2015a. Towards integrated performance evaluation of future packaging for fresh produce in the cold chain. Trends Food Sci. Technol. 44. doi:10.1016/j.tifs.2015.04.008

Defraeye, T., Lambrecht, R., Delele, M.A., Tsige, A.A., Opara, U.L., Cronjé, P., Verboven, P., Nicolai, B., 2014. Forced-convective cooling of citrus fruit: Cooling conditions and energy consumption in relation to package design. J. Food Eng. 121, 118-127. doi:10.1016/j.jfoodeng.2013.08.021

Defraeye, T., Lambrecht, R., Tsige, A.A., Delele, M.A., Opara, U.L., Cronjé, P., Verboven, P., Nicolai, B., 2013. Forced-convective cooling of citrus fruit: Package design. J. Food Eng. 118, 8-18. doi:10.1016/j.jfoodeng.2013.03.026

Defraeye, T., Verboven, P., Opara, U.L., Nicolai, B.M., Cronjé, P., 2015b. Feasibility of ambient loading of citrus fruit into refrigerated containers for cooling during marine transport. Biosyst. Eng. 134, 20-30. doi:10.1016/j.biosystemseng.2015.03.012

Delele, M.A., Ngcobo, M.E.K., Getahun, S.T., Chen, L., Mellmann, J., Opara, U.L., 2013. 
Studying airflow and heat transfer characteristics of a horticultural produce packaging system using a 3-D CFD model. Part II: Effect of package design. Postharvest Biol. Technol. 86, 546-555. doi:10.1016/j.postharvbio.2013.08.015

Delele, M.A., Ngcobo, M.E.K., Opara, U.L., Meyer, C.J., 2012. Investigating the effects of table grape package components and stacking on airflow, heat and mass transfer using 3-D CFD modelling. Food Bioprocess Technol. 6, 2571-2585. doi:10.1007/s11947012-0895-5

Delele, M.A., Tijskens, E., Atalay, Y.T., Ho, Q.T., Ramon, H., Nicolai, B.M., Verboven, P., 2008. Combined discrete element and CFD modelling of airflow through random stacking of horticultural products in vented boxes. J. Food Eng. 89, 33-41. doi:10.1016/j.jfoodeng.2008.03.026

ElMasry, G., Wang, N., Vigneault, C., 2009. Detecting chilling injury in Red Delicious apple using hyperspectral imaging and neural networks. Postharvest Biol. Technol. 52, 1-8. doi:10.1016/j.postharvbio.2008.11.008

Fadiji, T., Coetzee, C., Chen, L., Chukwu, O., Opara, U.L., 2016. Susceptibility of apples to bruising inside ventilated corrugated paperboard packages during simulated transport damage. Postharvest Biol. Technol. 118, 111-119. doi:10.1016/j.postharvbio.2016.04.001

Ferrua, M.J., Singh, R.P., 2011. Improved airflow method and packaging system for forced-air cooling of strawberries. Int. J. Refrig. 34, 1162-1173. doi:10.1016/j.ijrefrig.2011.01.018

Ferrua, M.J., Singh, R.P., 2009. Modeling the forced-air cooling process of fresh strawberry packages, Part I: Numerical model. Int. J. Refrig. 32, 335-348. doi:10.1016/j.ijrefrig.2008.04.010

Franke, J., Hellsten, A., Schlünzen, H., Carissimo, B., 2007. Best practice guidelines for 
the CFD simulation of flows in the urban environment. COST Action 732 Qual. Assur. Improv. microscale Meteorol. Model. Hamburg, Ger.

Goossens, Y., Berrens, P., Custers, K., Van Hemelryck, S., Kellens, K., Geeraerd, A., 2018. How origin, packaging and seasonality determine the environmental impact of apples, magnified by food waste and losses. Int. J. Life Cycle Assess. 1-21. doi:https://doi.org/10.1007/s11367-018-1522-0

Gowda, B.S., Narasimham, G.S.V.L., Murthy, M.V.K., 1997. Forced-air precooling of spherical foods in bulk: A parametric study. Int. J. Heat Fluid Flow 18, 613-624. doi:10.1016/S0142-727X(97)00028-3

Han, J.W., Zhao, C.J., Yang, X.T., Qian, J.P., Fan, B.L., 2015. Computational modeling of airflow and heat transfer in a vented box during cooling: Optimal package design. Appl. Therm. Eng. 91, 883-893. doi:10.1016/j.applthermaleng.2015.08.060

Hanlon, J.F., Kelsey, R.J., Forcinio, H., 1998. Handbook of package engineering, 3rd ed. CRC Press, Florida, USA.

Ho, S.H., Rahman, M.M., Sunol, A.K., 2010. Analysis of thermal response of a food selfheating system. Appl. Therm. Eng. 30, 2109-2115. doi:10.1016/j.applthermaleng.2010.05.020

Ingwersen, W.W., 2012. Life cycle assessment of fresh pineapple from Costa Rica. J. Clean. Prod. 35, 152-163. doi:10.1016/j.jclepro.2012.05.035

Lu, L., Chen, X., Wang, J., 2016. Modelling and thermal analysis of tray-layered fruits inside ventilated packages during forced-air precooling. Packag. Technol. Sci. 29, 105-119. doi:10.1002/pts.2189

Ngcobo, M.E.K., Delele, M.A., Opara, U.L., Zietsman, C.J., Meyer, C.J., 2011. Resistance to airflow and cooling patterns through multi-scale packaging of table grapes. Int. J. Refrig. 35, 445-452. doi:10.1016/j.ijrefrig.2011.11.008 
Ngcobo, M.E.K., Opara, U.L., Thiart, G.D., 2012. Effects of Packaging Liners on Cooling Rate and Quality Attributes of Table Grape (cv. Regal Seedless). Packag. Technol. Sci. 25, 73-84. doi:10.1002/pts.961

O’Sullivan, J., Ferrua, M.J., Love, R., Verboven, P., Nicolaï, B., East, A., 2017. Forced-air cooling of polylined horticultural produce: Optimal cooling conditions and package design. Postharvest Biol. Technol. 126, 67-75. doi:10.1016/j.postharvbio.2016.11.019

O’Sullivan, J., Ferrua, M.J., Love, R., Verboven, P., Nicolaï, B., East, A., 2016. Modelling the forced-air cooling mechanisms and performance of polylined horticultural produce. Postharvest Biol. Technol. 120, 23-35. doi:10.1016/j.postharvbio.2016.05.008

Pathare, P.B., Berry, T., Opara, U.L., 2016. Changes in moisture content and compression strength during storage of ventilated corrugated packaging used for handling apples. Packag. Res. 1, 1-6. doi:10.1515/pacres-2016-0001

Pathare, P.B., Opara, U.L., Vigneault, C., Delele, M.A., Al-Said, F.A., 2012. Design of Packaging Vents for Cooling Fresh Horticultural Produce. Food Bioprocess Technol. 5, 2031-2045. doi:10.1007/s11947-012-0883-9

Ramaswamy, H.S., Tung, M.A., 1981. Thermophysical properties of apples in relation to freezing. J. Food Sci. 46, 724-728.

Redding, G.P., Yang, A., Shim, Y.M., Olatunji, J., East, A., 2016. A review of the use and design of produce simulators for horticultural forced-air cooling studies. J. Food Eng. 190, 80-93. doi:10.1016/j.jfoodeng.2016.06.014

Roache, P.J., 1994. Perspective: a method for uniform reporting of grid refinement studies. J. Fluids Eng. 116, 405-413.

Robertson, G.L., 2013. Food Packaging: Principles and Practice, Third. ed. Taylor \& Francis Group LLC, Boca-Raton. 
Tanner, D.J., Cleland, A.C., Opara, U.L., Robertson, T.R., 2002. A generalised mathematical modelling methodology for design of horticultural food packages exposed to refrigerated conditions: part 1, formulation. Int. J. Refrig. 25, 33-42. doi:10.1016/S0140-7007(01)00019-6

Thompson, J.F., Mitchell, F.G., Rumsey, T.R., Kasmire, R.F., Crisosto, C.H., 2008. Commercial cooling of fruits, vegetables, and flowers. University of California, California.

van der Sman, R.G.M., 2002. Prediction of airflow through a vented box by the DarcyForchheimer equation. J. Food Eng. 55, 49-57. doi:10.1016/S0260-8774(01)00241-2 Wu, W., Cronjé, P., Nicolai, B., Verboven, P., Opara, U.L., Defraeye, T., 2018a. Virtual cold chain to model the postharvest temperature history and quality evolution of fresh fruit - A case study for citrus fruit packed in a single carton. Comput. Electron. Agric. 144, 199-208. doi:10.1016/j.compag.2017.11.034

Wu, W., Defraeye, T., 2018. Identifying heterogeneities in cooling and quality evolution for a pallet of packed fresh fruit by using virtual cold chains. Appl. Therm. Eng. 133, 407-417. doi:10.1016/j.applthermaleng.2017.11.049

Wu, W., Häller, P., Cronjé, P., Defraeye, T., 2018b. Full-scale experiments in forced-air precoolers for citrus fruit: impact of packaging design and fruit size on cooling rate and heterogeneity. Biosyst. Eng. 169, 115-125. doi:10.1016/j.biosystemseng.2018.02.003 


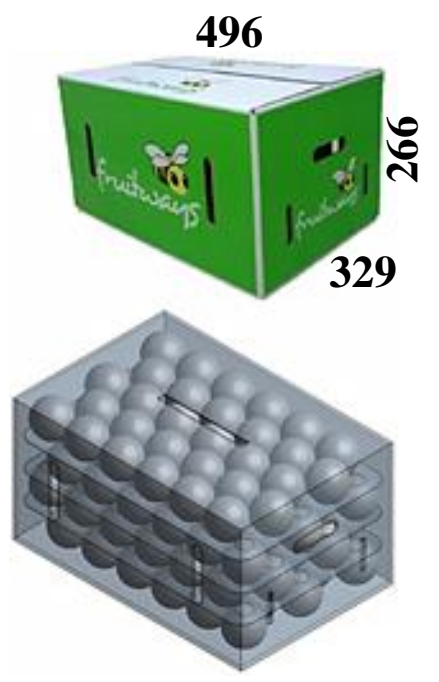

Mk4

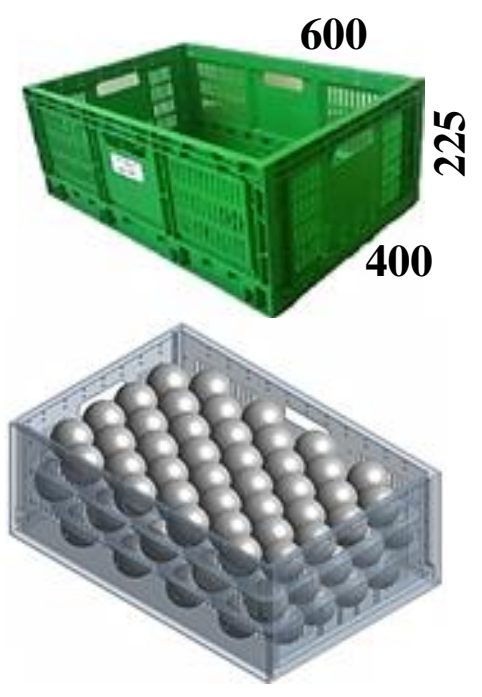

RPC

Figure 1: The outer dimensions (in $\mathbf{m m}$ ) of the two package designs for South African 'Granny Smith' apples. The top row shows the external dimensions (in $\mathrm{mm}$ ) of the two boxes, the bottom row shows the geometric model of the loaded boxes. The Mk4 and RPC are loaded with $20.2 \pm$ $0.7 \mathrm{~kg}$, and $20.4 \pm 0.7 \mathrm{~kg}$ of apples, respectively.
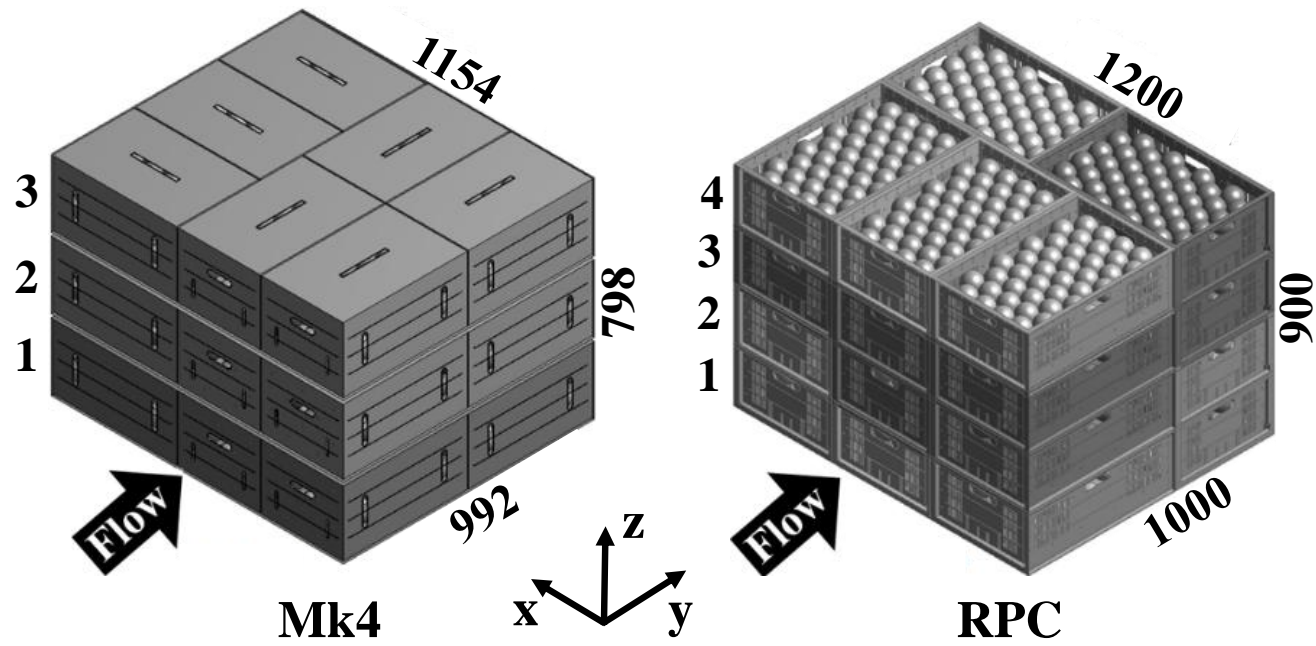

Figure 2: Stacking pattern of the two package designs ready for precooling. The external dimensions are shown in mm. The stack of Mk4 and RPC are loaded with about $424 \mathrm{~kg}$ and 410 $\mathrm{kg}$, respectively. 


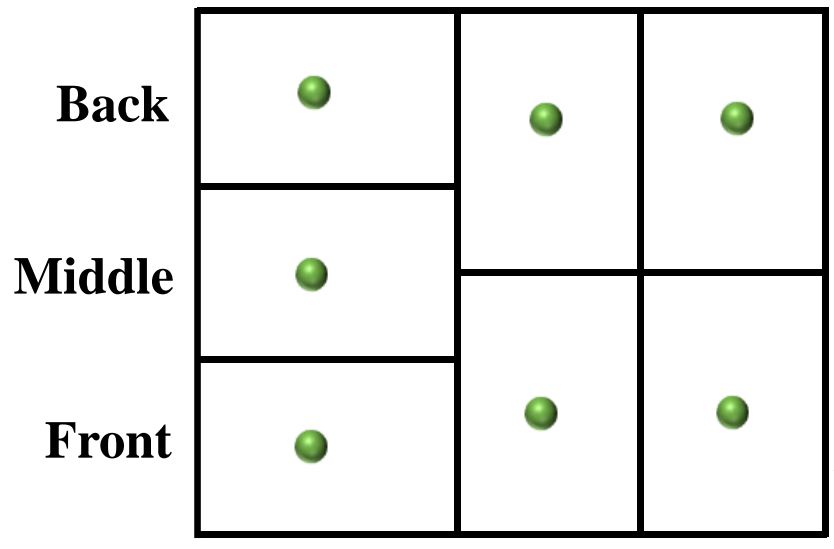

Mk4

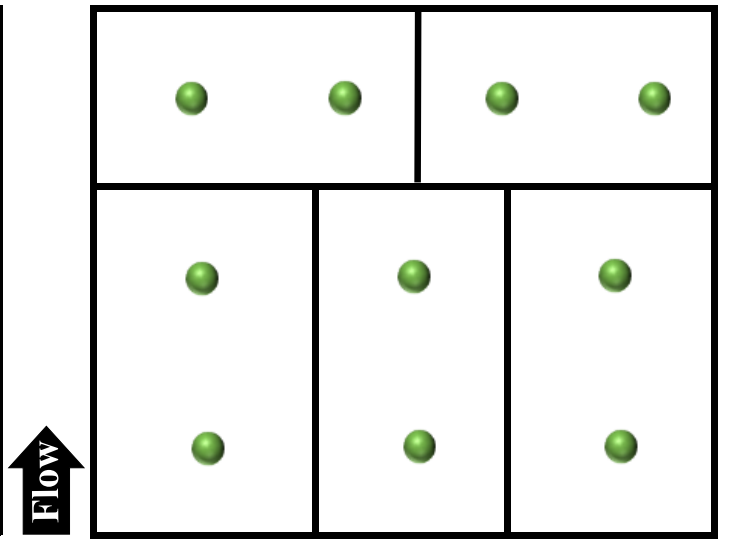

RPC

Figure 3: Schematic overview of the sample locations to monitor the temperature history of the produce during precooling of apple fruit as stacked in the two package designs. Produce temperatures were obtained by inserting thermocouples into the core of the sample fruit, positioned on the top tray.

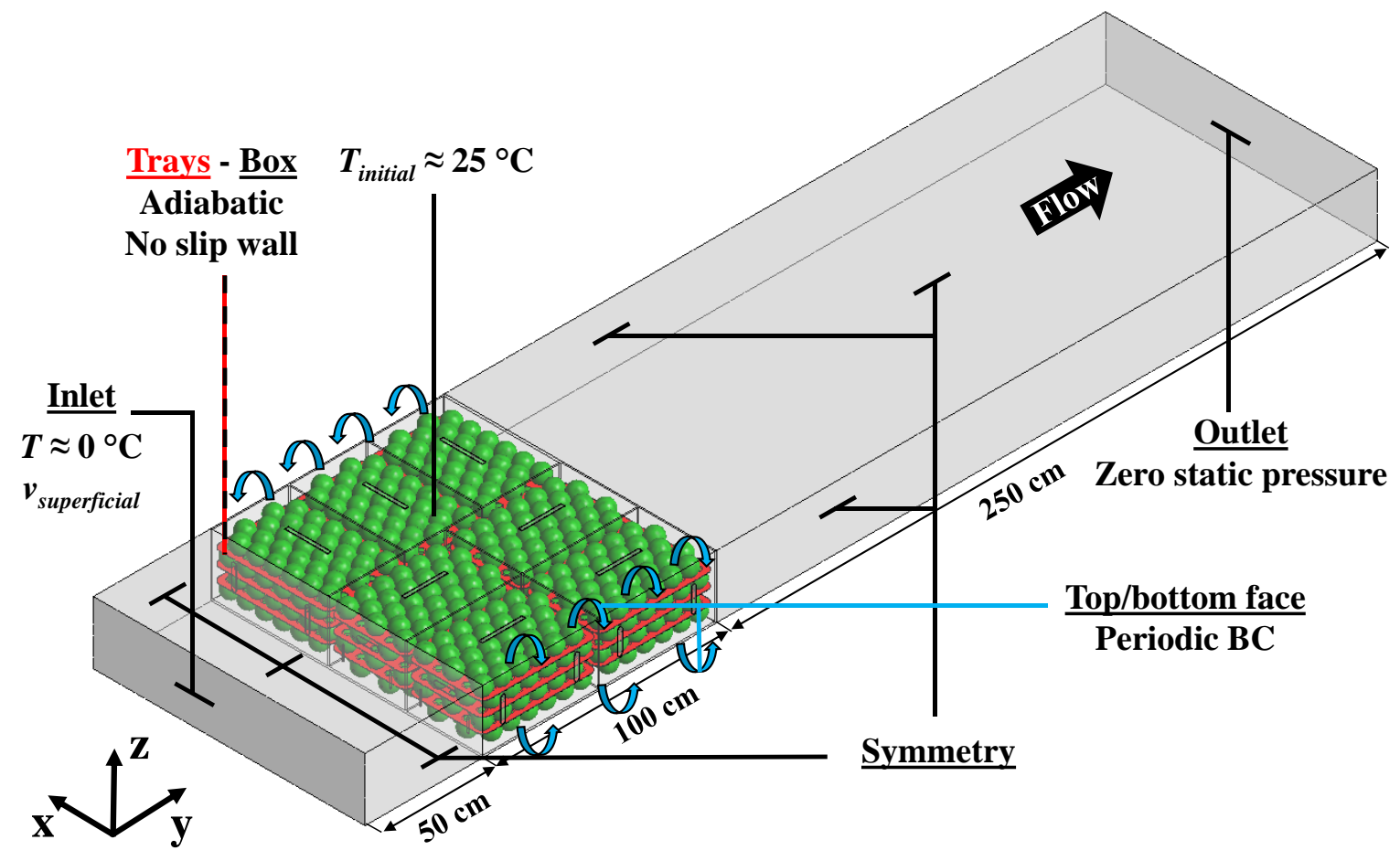

Figure 4: Schematic overview of the CFD model for a single Mk4 layer. The implemented boundary conditions for the RPC layer were analogous to the Mk4 layer. The air enters the computational domain from the left hand side. 


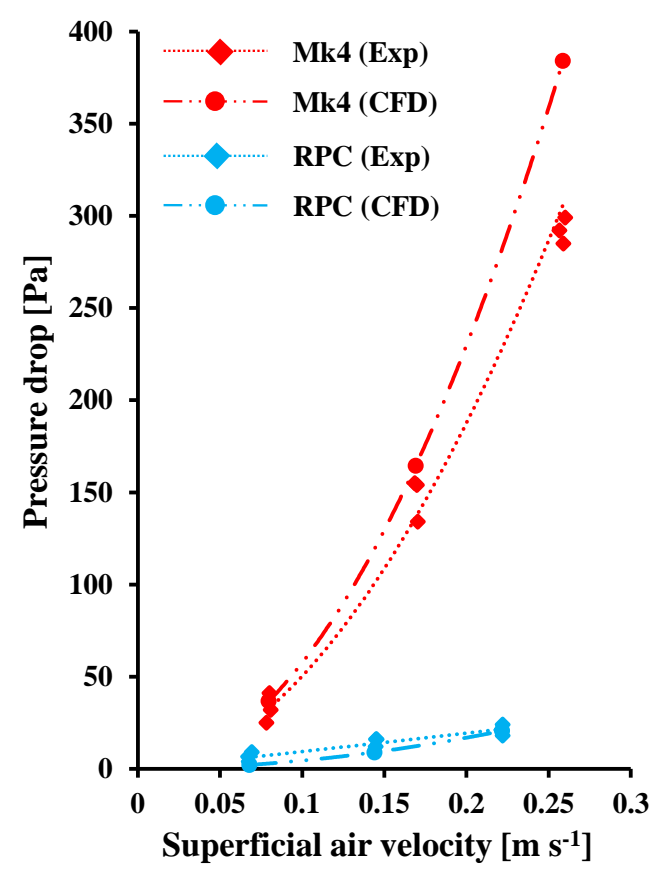

Figure 5: Pressure drop (Pa) over the stack of boxes as a function of superficial air velocity $(\mathrm{m} \mathrm{s}$ $\left.{ }^{1}\right)$ through the stack of containers for the two package designs. The data points (exp: $\bullet$, CFD: •) as well as the power-law approximation of the experiment and CFD model are shown. The equations of the power-law approximation are presented in Table 5. 

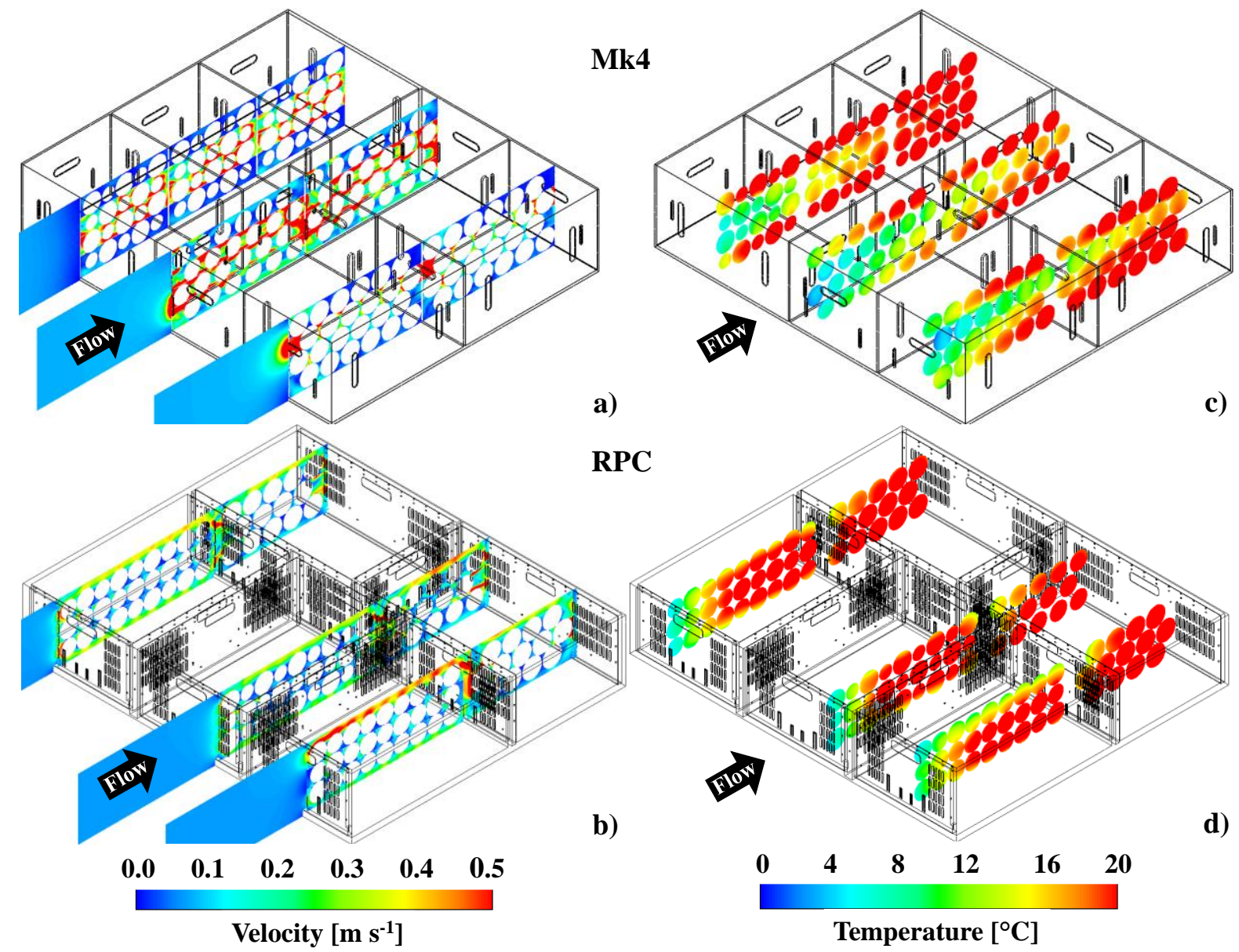

Figure 6: CFD results of velocity and temperature fields in apple boxes: left plots (a and b) show velocity contour plots on three distinct vertical planes in the stack at low airflow rate. Right plots (c and d) show fruit temperature contours on the same vertical planes after $2 \mathrm{~h}$ of cooling at low airflow rate. 
Experiment
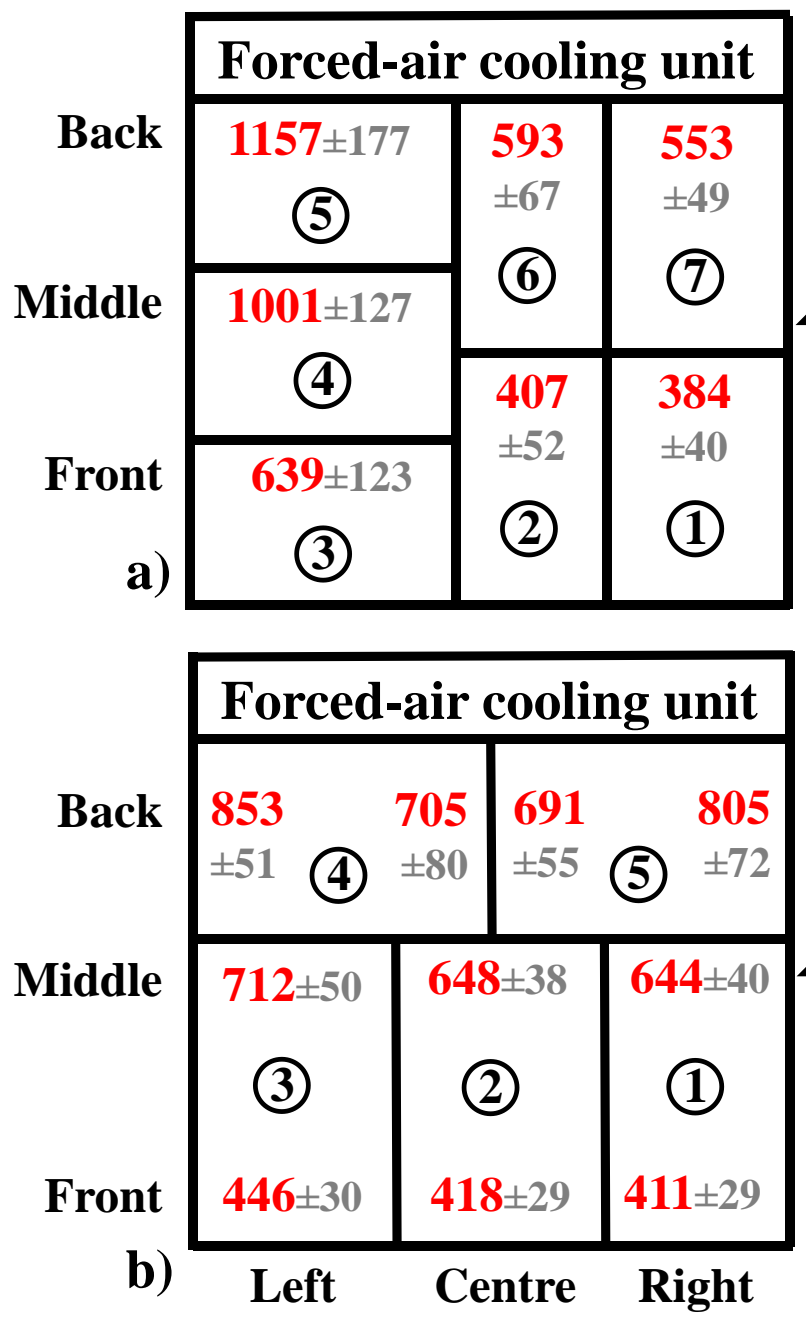

CFD

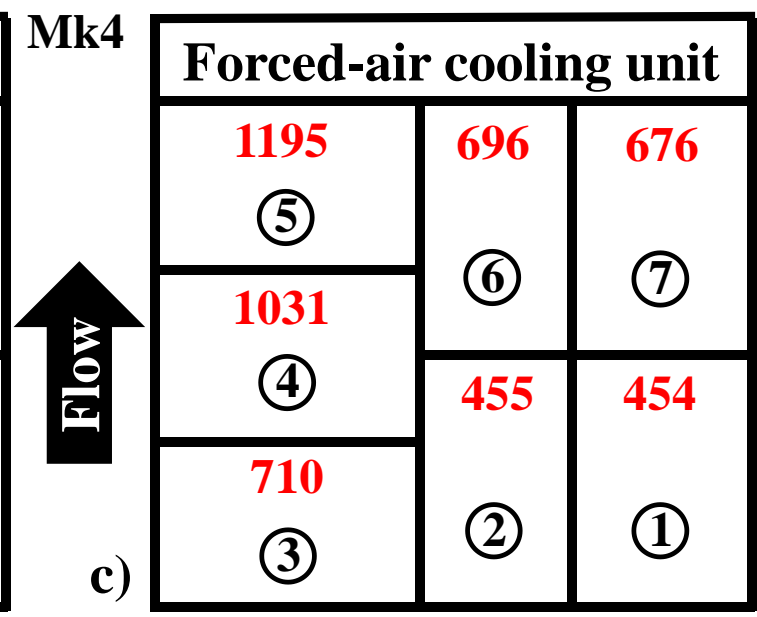

RPC

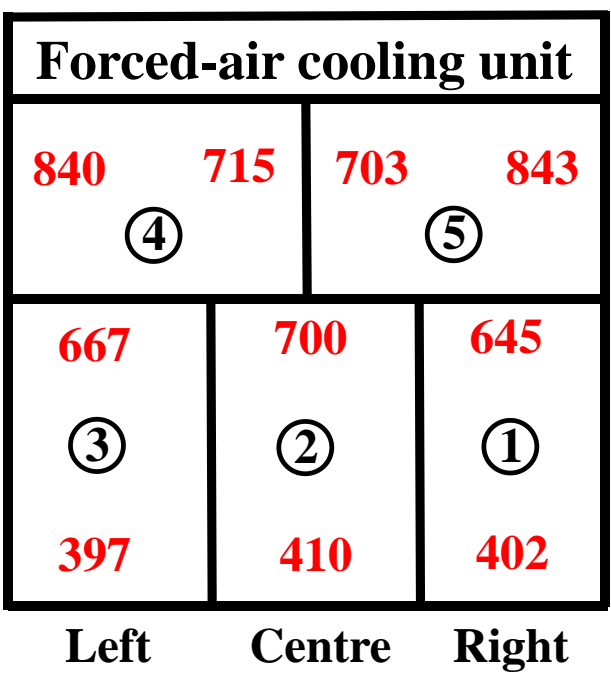

Figure 7: Schematic overview of the cooling rate of the two stacks. Left (a and b) Experimentally obtained seven-eighths cooling time $(\mathrm{min})$ in the sample fruit located in the topmost apple layer in the box with their corresponding standard deviation $(n=3$ repetitions $\times 3$ box layers) for each individual box in the stack during forced-air cooling at low superficial air velocity (values shown in Table 3); Right (c and d) - calculated seven-eighths cooling time (min) with the CFD model at the same positions as the experimentally obtained values. 

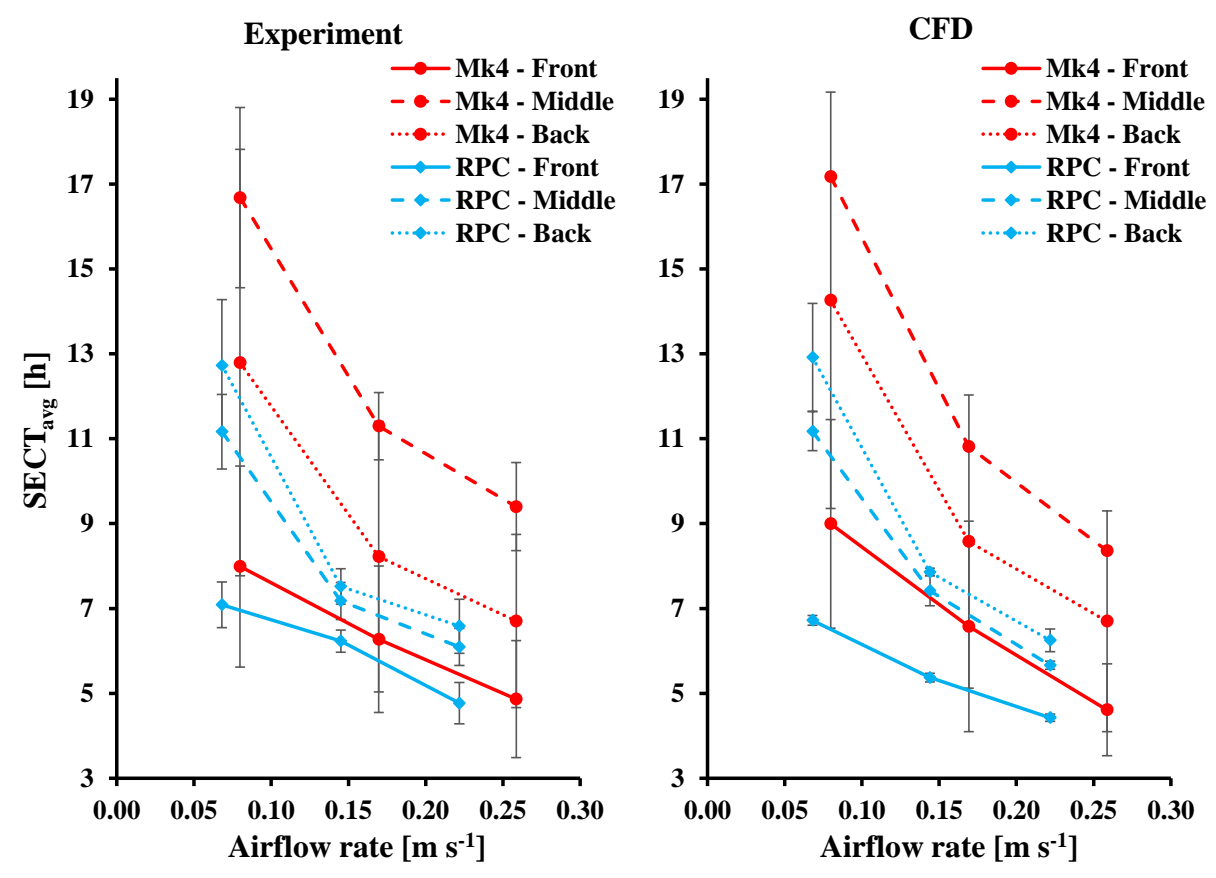

Figure 8: Average seven-eighths cooling time of the sample fruit located in the top-most apple layer of the boxes with the corresponding standard deviation ( $n=3$ repetitions $\times 3$ box layers) for the two box designs at three different streamwise locations in the layer (see Figure 3 ) for three different airflow rates.

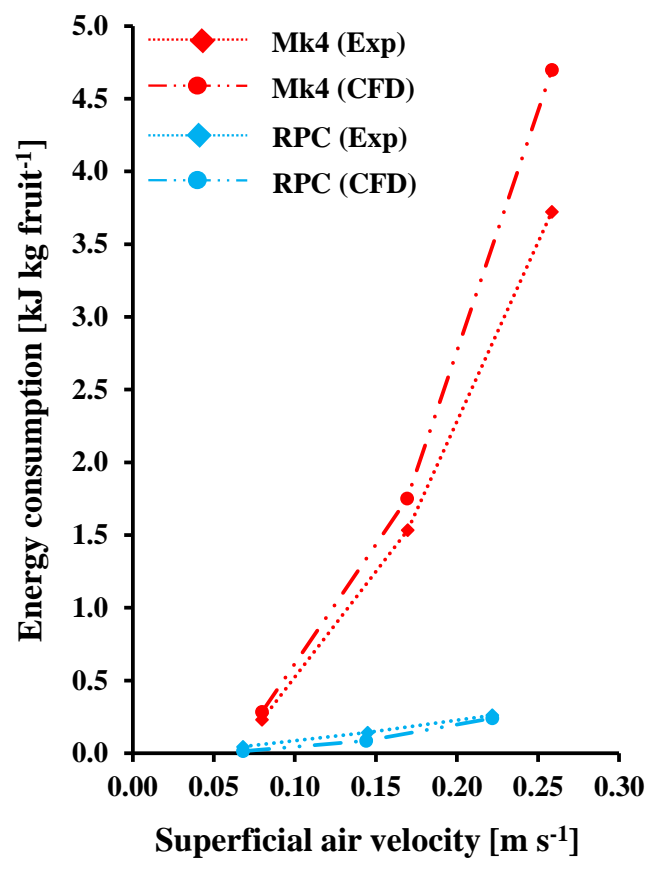

Figure 9: Energy requirement to maintain a certain superficial velocity through the stack of boxes. The values of the SECT of the stack used in the calculation are presented in Table 6 (Point values). 
Table 1: The loading capacities and vent hole characteristics of the two box designs (Figure 1).

\begin{tabular}{lcccc}
\hline & \multicolumn{2}{c}{ Mk4 } & \multicolumn{2}{c}{ RPC } \\
\hline Apples/box & \multicolumn{2}{c}{120} & \multicolumn{2}{c}{121} \\
weight/box $[\mathrm{kg}]$ & \multicolumn{2}{c}{$20.2 \pm 0.7^{1}$} & \multicolumn{2}{c}{$20.4 \pm 0.7^{2}$} \\
\hline Face(s) & \# Vents & TOA $(\%)$ & \# Vents & TOA $(\%)$ \\
\hline Long side & 2 & 3 & 109 & 17.1 \\
Short sides & 3 & 3.6 & 69 & 13.3 \\
Top & 1 & 1.7 & 1 & 100 \\
Bottom $^{3}$ & 1 & 6.4 & 220 & 12.3 \\
\hline
\end{tabular}

${ }^{1}$ Determined by measuring the weight of 567 apple fruit

${ }^{2}$ Determined by measuring the weight of 405 apple fruit

${ }^{3}$ The bottom face vents are blocked by the presence of a tray

Table 2: The stack characteristics of the two box designs (Figure 2).

\begin{tabular}{lcc}
\hline & Mk4 & RPC \\
\hline Number of boxes per layer & 7 & 5 \\
Number of layers per stack & 3 & 4 \\
Weight per stack [kg] & 424 & 410 \\
\hline
\end{tabular}

Table 3: The obtained superficial air velocity and measured pressure drop over the stack of boxes in the three different experiments with their respective standard deviation $(n=3$ repetitions). All measured pressure drops were statistically different $(p<0.002)$. Superficial air velocities depicted in 'bold' were implemented in the CFD model as a uniform inlet velocity boundary condition.

\begin{tabular}{cccc}
\hline \multicolumn{2}{c}{ Mk4 } & \multicolumn{2}{c}{ RPC } \\
\hline Superficial air velocity $\left(\mathrm{m} \cdot \mathrm{s}^{-1}\right)$ & Pressure drop $(\mathrm{Pa})$ & Superficial air velocity $\left(\mathrm{m} \cdot \mathrm{s}^{-1}\right)$ & Pressure drop $(\mathrm{Pa})$ \\
\hline $\mathbf{0 . 0 7 9 7} \pm 0.0014$ & $28 \pm 4$ & $\mathbf{0 . 0 6 8 0} \pm 0.0012$ & $6 \pm 3$ \\
$\mathbf{0 . 1 6 9 2} \pm 0.0012$ & $147 \pm 12$ & $\mathbf{0 . 1 4 5 0} \pm 0.0003$ & $15 \pm 2$ \\
$\mathbf{0 . 2 5 8 7} \pm 0.0018$ & $292 \pm 7$ & $\mathbf{0 . 2 2 1 8} \pm 0.0005$ & $21 \pm 3$ \\
\hline
\end{tabular}

Table 4: CFD model parameters

\begin{tabular}{|c|c|c|c|c|c|}
\hline Material & $\begin{array}{l}\text { Density } \\
{\left[\mathrm{kg} \mathrm{m}^{-3}\right]}\end{array}$ & $\begin{array}{l}\text { Thermal conductivity } \\
{\left[\mathrm{W} \mathrm{m}^{-1} \mathrm{C}^{-1}\right]}\end{array}$ & $\begin{array}{c}\text { Specific heat capacity } \\
{\left[\mathrm{J} \cdot \mathrm{kg}^{-1} \cdot{ }^{\circ} \mathrm{C}^{-1}\right]}\end{array}$ & Reference & \\
\hline Granny smith apple & 829 & 0.398 & 3580 & $\begin{array}{l}\text { Ramaswamy and } \\
\text { (1981) }\end{array}$ & Tung, \\
\hline RPC & 900 & 0.120 & 1925 & Ashby et al., (2009) & \\
\hline $\mathrm{Mk} 4$ & 145 & 0.064 & 1338 & Ho et al., (2010) & \\
\hline Air & 1.185 & 0.026 & 1004 & ASHRAE, (2006) & \\
\hline
\end{tabular}


Table 5: Power-law approximation of the pressure drop curves $(\Delta P)$ for the experiment and computational model (single layer of the two box designs) as a function of the superficial airflow rate $\left(U_{s}, \mathrm{~m} \mathrm{~s}^{-1}\right)$.

\begin{tabular}{llll}
\hline \multicolumn{2}{c}{ Container design } & Ramsin equation & Adjusted $\mathrm{R}^{2}$ \\
\hline \multirow{2}{*}{ Experiment } & Mk4 & $\Delta P=3986 U_{s}^{1.899}$ & 0.982 \\
& $\mathrm{RPC}$ & $\Delta P=105 U_{s}^{1.048}$ & 0.990 \\
\multirow{2}{*}{ CFD model } & Mk4 & $\Delta P=5695 U_{s}^{1.995}$ & 1.000 \\
& $\mathrm{RPC}$ & $\Delta P=370 U_{s}^{1.918}$ & 1.000 \\
\hline
\end{tabular}

Table 6: Average seven-eighths cooling time (in hours) of the two stacks for each airflow rate (AFR) presented for both experimental and CFD results. The "point" value was calculated by taken the average of all sample fruit located in the top-most apple layer in the box (see Figure $3)$. The "volume" value was calculated by taking the combined volume average temperature of all fruit in the entire layer of the stack.

\begin{tabular}{lcc|cc|c|c}
\hline & \multicolumn{2}{c|}{ Experiment } & \multicolumn{4}{c}{ CFD model } \\
& Mk4 point & RPC point & Mk4 point & RPC point & Mk4 volume & RPC volume \\
\hline Low AFR & 11.34 & 10.59 & 12.42 & 10.54 & 10.16 & 11.40 \\
Medium AFR & 7.83 & 7.03 & 8.04 & 6.98 & 6.79 & 7.81 \\
High AFR & 6.30 & 5.89 & 6.04 & 5.53 & 4.90 & 6.24 \\
\hline
\end{tabular}

